\title{
Bond Coatings with High Rumpling Resistance: Design and Characterization
}

\author{
David J. Jorgensen ${ }^{1}$ \\ Materials Department, University of California, Santa Barbara, CA, USA \\ Akane Suzuki \\ GE Global Research, Niskayuna, NY, USA \\ Don M. Lipkin \\ GE Global Research, Niskayuna, NY, USA \\ Tresa M. Pollock \\ Materials Department, University of California, Santa Barbara, CA, USA
}

\begin{abstract}
The behavior of two new high-strength $\gamma^{\prime} \mathrm{Ni}_{3} \mathrm{Al}$-base bond coats have been compared to a baseline $\beta(\mathrm{Pt}, \mathrm{Ni}) \mathrm{Al}$ bond coat via thermal cycling to a maximum temperature of $1204^{\circ} \mathrm{C}$. The rumpling amplitude of the $\gamma^{\prime}$ coating is significantly lower than the (Pt,Ni)Al as characterized by a nondestructive optical profilometry technique. The $\gamma^{\prime}$ coatings resist rumpling and spallation of the thermally grown oxide in spite of faster oxidation compared to Pt-modified NiAl.

Keywords: bond coat design, nondestructive evaluation, oxidation, thermal barrier coating, rumpling
\end{abstract}

\section{Introduction}

Bond coats are an integral component of the thermal barrier coating (TBC) system in turbine engines and must satisfy two main requirements. First and foremost, the coating acts as a primer layer for the ceramic topcoat and provides compatibility with the underlying metallic superalloy [1]. Maintaining topcoat adhesion is paramount for protecting the superalloy from the high-temperature combustion environment. Second, a bond coat is required to protect the superalloy from the oxidizing atmosphere by serving as an aluminum reservoir from which the coating

\footnotetext{
${ }^{1}$ davidjjorgensen@engr.ucsb.edu,fax:(805)893-8486, phone:(805)893-2413
} 
may grow and maintain an $\alpha-\mathrm{Al}_{2} \mathrm{O}_{3}$ thermally grown oxide (TGO) [1]. Industry-standard coatings, MCrAlY and $\beta$-phase platinum-modified nickel aluminide ((Pt,Ni)Al, henceforth $\mathrm{PtAl})$, have been optimized for this latter requirement with a dense and slow-growing $\mathrm{Al}_{2} \mathrm{O}_{3}$ scale [1]. While the PtAl provides good oxidation and corrosion protection, it has modest high-temperature strength and is vulnerable to deformation in service [2]. As the surface temperature of TBCs is increased in pursuit of higher operating efficiency, rumpling is accelerated, leading to TBC failure [3] wherein the bond coat forms undulations of a characteristic wavelength due to a ratcheting creep mechanism during thermal cycling $[4,5]$. The ceramic topcoat, which has a low out-of-plane compliance, cannot deform with the bond coat and therefore detaches from the bond coat, leading to buckling, and subsequent spallation, resulting in loss of thermal protection. Bond coat creep is driven by the thermal expansion mismatch with the superalloy and thermally grown oxide during thermal cycling [5-9]. Analytical models indicate that the primary rumpling wavelength is a function of the system properties (elastic moduli, thermal expansion coefficients (CTE), thickness) [4] and has been commonly modeled as a 2D sinusoidal surface undulation that grows in amplitude [10]. Theoretical analysis indicates that increasing the yield and creep strengths of the bond coat will mitigate rumpling [7-9].

Another failure mechanism observed during thermomechanical cycling is crack initiation and growth through oxidation-assisted fatigue. Large through-thickness thermal gradients develop on internally cooled turbine blades during takeoff and landing cycles that put the outer surface into a state of compression at high temperature. Creep relaxation during the compressive hold results in a tensile stress upon release of the compressive strain, which can open surface cracks and promote crack face oxidization. The oxidized crack tips push into the coating and substrate upon the next compression cycle, as has been shown in sustained peak low-cycle fatigue (SPLCF) experiments $[11,12]$. Crack growth in this scenario is dependent on the superalloy and coating properties [12]. Modeling of the SPLCF experiments shows that increasing the creep strength of the bond coat will decrease the crack extension rate [13] even after the crack has penetrated completely into the substrate [14].

Modeling indicates that improving the yield strength and creep properties of the bond coat will mitigate both rumpling and oxidation assisted fatigue failure mechanisms of TBC systems on turbine components. To this end, a number of experimental coatings with compositions in the 
$\gamma^{\prime}-\mathrm{Ni}_{3} \mathrm{Al}$ phase field have been designed in order to investigate their high-temperature performance in comparison to $\beta-\mathrm{NiAl}$ coatings. The $\gamma^{\prime}$ phase has the $\mathrm{L} 1_{2}$ crystal structure, which is an ordered FCC. The principal advantage of $\gamma^{\prime}$ over $\beta$, which has the BCC-based B2 structure, is that the tighter atomic packing in $\mathrm{Ni}_{3} \mathrm{Al}$ results in an inherently slower diffusion rate, which should improve creep properties at high temperature [15-18]. Further, it has been shown that the yield strength of the $\gamma^{\prime}$ phase is significantly higher than that of the $\beta$ phase [19-22]. The focus of this manuscript will be on a comparison of the rumpling behavior of $\gamma^{\prime}$ and $\beta$ coatings.

The oxidation behavior of $\mathrm{Ni}_{3} \mathrm{Al}$ is less ideal than that of $\mathrm{NiAl}$ due to the formation of $\mathrm{NiAl}_{2} \mathrm{O}_{4}$ type (spinel) oxides upon thermal cycling of the former [23]. However, it is known that small additions of $\mathrm{Cr}$ improve the oxidation characteristics of $\mathrm{Ni}_{3} \mathrm{Al}$ by selectively forming and maintaining an $\mathrm{Al}_{2} \mathrm{O}_{3}$ scale $[24,25]$.

The objective of the present study was to design coatings that resist the high-temperature deformation that leads to rumpling and oxidation-assisted fatigue while maintaining adequate oxidation properties. The service life of a thermal barrier coating is ultimately determined by the weakest link in the interconnecting chain of mechanical properties, oxidation properties, and interlayer compatibility. We presently show that a $\gamma^{\prime}$ coating can resist rumpling during high temperature cyclic oxidation testing. The presence and absence of rumpling in PtAl and $\gamma^{\prime}$ coatings is characterized nondestructively throughout the test.

\section{Coating design}

The design of bond coats for TBCs, by necessity, requires a systems approach that considers the properties of each constituent of the multi-layered system. It is essential that the bond coat maintains adhesion to the overlying ceramic thermal barrier layer because the presence of the TBC drops the superalloy temperature as much as $300^{\circ} \mathrm{C}[26]$. The creep and oxidation rates of a superalloy will increase drastically after a TBC spall. Further, the temperature and oxidation increase will result in rapid disintegration of the superalloy substrate. Therefore, the design of bond coats for use in such systems must emphasize TBC adhesion. TBC adhesion stems from a combination of rumpling resistance and oxidation properties. The bond coat must have high temperature strength to resist out-of-plane deformation that the TBC cannot accommodate. Also, the bond coat must serve as an adequate $\mathrm{Al}$ reservoir from which to grow a TGO that is compatible 
with the TBC $\left(\mathrm{Al}_{2} \mathrm{O}_{3}\right)$. With this in mind, new bond coats that sacrifice an acceptable level of oxidation properties for the benefit of high-temperature strength were sought in order to improve the overall performance of the bond coat/TBC system.

Thermo-Calc Software with a TCNI5 Ni-based superalloys database [27] was used with a CalPhaD-based approach to explore $\gamma^{\prime}$ composition space and identify candidate coating compositions with a high likelihood of success at mitigating the rumpling and oxidation-assisted fatigue mechanisms outlined in Section 1. Pt and Pd were not considered for this investigation to demonstrate the feasibility of improving overall coating performance without the use of precious metals. The outline of the design process is as follows. First, elements known to stabilize the $\gamma^{\prime}$ phase (Ta, Mo, W, Ti, Hf), strengthen the $\gamma^{\prime}$ phase (Si, Hf, Ta, Ti) [28, 29], and have beneficial effects on the cyclic oxidation behavior of $\mathrm{NiAl}$ or $\mathrm{Ni}_{3} \mathrm{Al}$ (Cr, Si, Zr, Hf, Y) [30-33] were considered as potential alloying additions. Second, because bond coats are continuously depleted of Al during service by oxidation and interdiffusion with the substrate, the candidate alloying elements were evaluated for their relative $\gamma^{\prime}$ stabilization efficacy as measured by the total width of the $\gamma^{\prime}$ field as a function of $\mathrm{Al}$ (in an isopleth). Stabilizing the $\gamma^{\prime}$ phase ensures the coatings maintain high strength for a greater fraction of service life. Third, the change in the solidus temperature as a function of alloying composition was evaluated to avoid incipient melting during post-coating annealing heat treatments or service. In all, thousands of compositions were screened for interdiffusion compatibility with the superalloy René N5 before selecting a base composition $\left(\gamma^{\prime}\right)$ and a second composition having additional solid solution strengtheners $\left(\gamma^{\prime}+\mathrm{Si}, \mathrm{Ti}\right)$ whose experimentally measured chemistry is listed in Table 1. The amount of each alloying element was an attempt to optimize a multiparameter space - solidus, high-temperature strengthening, oxidation, and substrate interdiffusion (via matching the chemical activity at $1150^{\circ} \mathrm{C}$ ).

\section{Experimental}

The coatings were deposited onto (001) single crystal René N5 disk substrates $(\varnothing=19.1 \mathrm{~mm}$, $h=2.1 \mathrm{~mm}$ ) using ion plasma deposition [34]. The samples were vacuum heat treated for four hours at $1080^{\circ} \mathrm{C}$. A standard PtAl coating $(\varnothing=25.4 \mathrm{~mm}, h=3.2 \mathrm{~mm})$ made by electroplating Pt onto René N5 followed by vapor phase aluminization was used as a standard for comparison. All coatings were grit blasted with a standard grit blasting procedure using 220 grit alumina particles 
prior to testing. The specimens were ultrasonically cleaned for twenty minutes in methanol before being thermally cycled 120 times at $1204^{\circ} \mathrm{C}$ in an air atmosphere. The hour-long thermal cycle consisted of a ten-minute ramp from room temperature to $1204^{\circ} \mathrm{C}$ followed by a forty-four minute hold and six minutes of cooling by forced ambient air, reaching a minimum inter-cycle temperature of $70^{\circ} \mathrm{C}$. Cyclic oxidation testing was carried out in a bottom-loading Rapid Temp furnace (CM Furnaces). An interrupted test was conducted to 60 cycles and showed good repeatability.

The samples were periodically removed for analysis and the mass, surface profile, oxide coverage, and surface phase constitution were measured using a balance, Alicona InfiniteFocus optical profilometer, SEM, and XRD. The profilometer has a vertical resolution of tens of nanometers and a lateral resolution of hundreds of nanometers.

Cross sections showing the microstructures of the two experimental coatings in the as-heat treated condition are shown in Figure 1. Both of the nominally $\gamma^{\prime}$ coatings were slightly Al-rich and therefore contain a small amount of secondary $\beta$-phase. Some of the surplus $\mathrm{Al}$ in these coatings diffused into the substrate during the heat treatment and no $\beta$ phase was detected by the end of the first thermal cycle.

\subsection{Characterization of surface topology}

Characterization of the progressive rumpling was investigated using a custom-coded Mathematica program to calculate Fourier transforms (FTs) of the surface profiles. An area of approximately $5 \times 1 \mathrm{~mm}$ near the center of each sample was measured with the optical profilometer and converted to a $2 \mathrm{D}$ matrix of height values having dimension $5893 \times 1238$. Figure $2 \mathrm{a}$ is an example surface profile from the PtAl coating taken after 120 cycles. The matrix of height values was zero-padded around the perimeter to dimensions of $6000 \times 6000$ points to increase the frequency resolution upon transformation and ensure that the frequency sampling was the same in all directions after the FT. A discrete Fourier transform of each matrix was computed, shifted to DC-center the data (Figure

$2 \mathrm{~b}$ ), and then radially averaged to collect the information from all directions along the surface (Figure 2c). The radially averaged FTs of the surface profiles of subsequent cycles were normalized by the radially averaged $\mathrm{FT}$ at the 0 th cycle $\left(\mathrm{FT}_{120 \mathrm{c}} / \mathrm{FT}_{0 \mathrm{c}}-1\right)$ to quantify the evolution of surface topology during the test (Figure 2d). A 500-point moving average was drawn through the resulting values in frequency space to eliminate noise associated with the uneven padding of the initial matrices and the normalization of the transforms. The Fourier transform represents the spectrum 
of sinusoidal components needed to represent the surface topology. The peak value of these curves, $\delta_{\max } / \delta_{0}$, which corresponds to the frequencies/wavelengths that experienced the largest amplitude increase during the test, is measured to give the primary rumpling wavelength and the extent to which rumpling has proceeded throughout the test. The FT algorithm is described in greater detail and benchmarked against common rumpling descriptors elsewhere [35]. It is found to give a more accurate description of bond coat rumpling throughout a cyclic oxidation experiment compared to the surface tortuosity or average surface roughness descriptors.

\subsection{Characterization of oxide spalling}

The amount of spalled surface oxide was measured using a backscattered electron (BSE) SEM. The freshly exposed metallic surface appears bright in comparison to the oxide scales, as shown after 120 cycles in low magnification images in Figure 3. These images were segmented into binary images of oxide and exposed alloy using basic image processing. The area fraction of exposedcoating pixels was calculated, which is the area fraction of alloy freshly exposed during that cycle due to cracking and spalling of the oxide scale upon cooling. The total amount of bond coat that was exposed throughout the test (or total amount of failed TGO-bond coat interface) was quantified by integrating these values using first-order interpolation between measurements. This is a measure of the cumulative total fraction of the bond coat-TGO interface that has failed throughout the test.

\section{Results}

In terms of TGO adherence, as detailed in the following sections, the results of cyclic oxidation testing indicate that the $\gamma^{\prime}$ coating without Si and Ti additions formed the most protective TGO. Cross section micrographs of the coatings in the interrupted test (60 cycles) and at the end of the test (120 cycles) are given in Figures 4 and 5. While the $\gamma^{\prime}$ coatings oxidized more rapidly than the PtAl coating, the $\gamma^{\prime}$ coatings exhibited less rumpling.

\subsection{Mass gain}

The mass of each sample changes due to the formation and local spallation of TGO. The surface area-normalized mass change of the three coatings is shown in Figure 6a. Both of the $\gamma^{\prime}$ coatings gained mass faster than the PtAl coating. The PtAl sample gained mass continually throughout 
the test, despite clear evidence of oxide spalling, Figure 6; this is discussed in more detail in Section 4.4 .

\subsection{Surface topology}

The root-mean-square (RMS) surface roughness $\mathrm{S}_{\mathrm{q}}$ is shown in Figure $7 \mathrm{a}$ as a function of cycles, where

$$
S_{q}=\sqrt{\frac{1}{M N} \sum_{k=0}^{M-1} \sum_{i=0}^{N-1} z\left(x_{k}, y_{i}\right)^{2}}
$$

$z\left(x_{k}, y_{i}\right)$ is the height of each pixel, $M$ is the number of pixels in the $k$ direction, and $N$ is the number of pixels in the $i$ direction. Previous characterization of the rumpling of MCrAlY and (Pt,Ni)Al bond coats has successfully used the RMS surface roughness of the TGO as an indicator of bond coat rumpling $[5,36,37]$. This type of analysis can be a good indicator of bond coat rumpling because the TGO in these systems is thin, dense, and homogeneous, such that the top surface of the TGO accurately follows the undulations in the bond coat. However, the RMS roughness is a poor indicator of rumpling when the TGO is not homogeneous and the thickness of the TGO is on order of the bond coat undulations. In this case, the roughness of the top surface of the TGO is dominated by the local topology of the oxide scale rather than by deformation of the bond coat.

A second commonly used metric to quantify bond coat rumpling is the 1D tortuosity of the TGO measured from a cross sectioned metallographic sample. This value can be calculated nondestructively using the $2 \mathrm{D}$ surface tortuosity from a surface profile scan. The $2 \mathrm{D}$ tortuosity $\left(\mathrm{A} / \mathrm{A}_{0}\right)$ of the oxide surface is defined as the ratio of the $3 \mathrm{D}$ surface area $A$ to the $2 \mathrm{D}$ projection of the surface $\mathrm{A}_{0}\left(=M \times N \times \delta^{2}\right)$. The tortuosity measurements as a function of cycle number are in Figure $7 \mathrm{~b}$. The tortuosity of the PtAl coating increases monotonically throughout the test as rumpling causes an increase in the surface area of the coating due to the growth of undulations. This indicates that the bond coat continually deformed (rumpled) throughout the test and the uniform oxide layer deformed with it. However, this metric is subject to the same pitfall as $S_{q}$ because it only analyzes the surface of the TGO. When the TGO is nonuniform, such as is the case with these experimental coatings, the tortuosity values are noisy and inconsistent because the surface area of the TGO does not accurately represent the surface area of the bond coat.

A more reliable means of describing the surface behavior employs a Fourier transform analysis of the surface as described in section 3.1. The FT is more informative because it separates the 
individual contributions of every wavelength to the total surface topology rather than amalgamating all of them into an oversimplified descriptor. Thus, the large-scale deformation of the bond coat is easily distinguished from the random small-scale inhomogeneities of a poorly-forming TGO scale. The power of the FT algorithm is that it can effectively measure the large scale periodic undulations of the bond coat even underneath a thick TGO. Bond coat deformation results in a FT signature increase at low frequencies while TGO inhomogeneities only impact the high frequency values of the FT. Figure 8 is a plan-view optical image of the coatings where the TGO inhomogeneities are clearly visible, indicating that a means to separate the TGO inhomogeneities from the systematic deformation of the bond coat is needed.

As described in Section 3.1, the radially averaged FTs of the coatings were normalized by the 0cycle curves so that the change in surface topology is quantified. Taking the value of the peak gives a measure of the amount that the dominant surface wavelength increases in amplitude throughout the test. These measurements are presented in Figure $9 \mathrm{a}$ and the primary rumpling wavelength is presented in Figure 9b. The baseline PtAl coating experienced significant rumpling at a relatively constant wavelength while the two experimental $\gamma^{\prime}$ coatings showed substantially less rumpling at increasing wavelengths.

\subsection{Evolution of coatings and thermally grown oxides}

Results of the XRD phase analysis are shown in Figure 10. The $\gamma^{\prime}$ and $\gamma^{\prime}+\mathrm{Si}$,Ti coatings began with $\gamma^{\prime}+\beta$ phases and $\mathrm{HfO}_{2}$ particles after deposition and heat treatment and lost Al during thermal cycling due to interdiffusion with the substrate and formation of the TGO. Analysis indicated that the $\gamma^{\prime}$ coating contained monoclinic $\mathrm{HfO}_{2}$ and the $\gamma^{\prime}+\mathrm{Si}$,Ti coating had monoclinic and orthorhomic $\mathrm{HfO}_{2}$. The $\gamma^{\prime}$ coating maintained the $\gamma^{\prime}-\mathrm{Ni}_{3} \mathrm{Al}$ phase throughout the test whereas the $\gamma^{\prime}+\mathrm{Si}, \mathrm{Ti}$ coating transitioned to a solid solution of $\gamma$-Ni at around 60 cycles. Both the $\gamma^{\prime}$ and $\gamma^{\prime}+\mathrm{Si}$,Ti coatings produced thermally grown oxide scales that were predominately $\alpha-\mathrm{Al}_{2} \mathrm{O}_{3}$ with an intermixing of other oxides. The $\gamma^{\prime}$ coating contained trace amounts of $\mathrm{Ta}_{2} \mathrm{O}_{5}$ throughout the test but showed a continuous increase in the size of the $\mathrm{NiAl}_{2} \mathrm{O}_{4}$ peaks. $\mathrm{HfO}_{2}$ pegs formed underneath the oxide scales and at the surfaces of both $\gamma^{\prime}$ coatings due to the selective oxidation of Hf. In addition, both of the $\gamma^{\prime}$ coatings formed a discontinuous layer of nickel aluminate spinel $\left(\mathrm{NiAl}_{2} \mathrm{O}_{4}\right)$ on top of the corundum layer. Based on the shift in diffraction peaks, the Ni spinel transitioned to an intermixed layer of $\mathrm{Ni}$ and Co spinel on the $\gamma^{\prime}$ coating near the end of life by diffusion of Co from 
the superalloy substrate through the coating and $\mathrm{Al}_{2} \mathrm{O}_{3}$ layers. The $\gamma^{\prime}+\mathrm{Si}$,Ti coating formed rutile $\mathrm{TiO}_{2}$ immediately upon cycling and a small amount of $\mathrm{HfTiO}_{4}$ within the first 10-30 cycles. The rutile dominated the top of the coating at the end of life, as seen by the pale blue color in Figure 8. These layers of oxides are porous and have lower elastic moduli than $\mathrm{Al}_{2} \mathrm{O}_{3}$ and therefore may be beneficial in decreasing TGO spalling due to decreased energy release rate upon cooling. However, rutile would likely be detrimental to $\mathrm{TBC}$ adhesion because the mutual solubility of $\mathrm{TiO}_{2}$ and $\mathrm{ZrO}_{2}$ would lead to a degradation of the TBC/TGO interface [38].

\subsection{Spallation of thermally grown oxide}

The area fraction of TGO that spalled from the surface of the bond coat upon cooling was analyzed periodically throughout the test, as explained in Section 3.2. The results of these measurements were integrated with linear interpolation as a function of cycles and are plotted in Figure 6b. This type of analysis gives a cumulative measure of the quantity of TGO that has spalled from the metallic surface and has regrown during the test. However, this measurement does not include any loss of oxide that may have occurred due to loss of cohesion within the oxide scale itself. By the end of the 120 cycles, the $\gamma^{\prime}$ coating experienced the lowest cumulative spalling, followed by the PtAl coating and the $\gamma^{\prime}+\mathrm{Si}$,Ti coating. Plan view images of the four coatings at 120 cycles are shown in Figure 3; these images give a sense of the simplicity with which this technique can be used to segment out the exposed bond coat from the oxide layer as well as the relative performance of the coatings with regards with maintaining the oxide scale.

\section{Discussion}

\subsection{Oxidation behavior}

In comparison with the PtAl coating, which grew predominately $\alpha-\mathrm{Al}_{2} \mathrm{O}_{3}$ throughout the test, the oxide scales grown on the $\gamma^{\prime}$ coatings consisted primarily of $\alpha-\mathrm{Al}_{2} \mathrm{O}_{3}$ with $\mathrm{HfO}_{2}$ pegs that were selectively oxidized below the surface and eventually overtaken and enveloped by the scale. Ni and Co-rich spinels formed on top of the alumina scale throughout the test, likely due to enhanced diffusion through the TGO at high-angle grain boundaries. These oxides created a thin layer across the top surface of the samples and formed small clumps of oxide randomly distributed across the surface (see Figure 8). 


\subsection{Evaluation of Balint and Hutchinson rumpling model}

Rumpling is a complex phenomenon that is the result of the interactions between several material properties and processes such as CTE mismatches, heating/cooling rates, diffusion/creep, TGO growth and growth strain, and bond coat strength. The Balint and Hutchinson $(\mathrm{B} \& \mathrm{H})$ rumpling model is the most comprehensive attempt to resolve these competing interactions and can be used to draw insight from the coating rumpling behavior exhibited in the present experiments $[4,6]$. However, a critical comparison of theory and experiment must be made before deriving insight from the analytical model of $\mathrm{B} \& \mathrm{H}$. To date, the most complete set of experiments elucidating the rumpling behavior of PtAl bond coats was conducted by Tolpygo and Clarke (T\&C) [5]. This series of experiments included thermal cycling with various high-temperature holds, cycling above the martensitic transition temperature, and cycling under vacuum. These sets of experiments provide an excellent opportunity to evaluate the $\mathrm{B} \& \mathrm{H}$ model. In short, the $\mathrm{B} \& \mathrm{H}$ model accounts for

rumpling rate, $\dot{\delta}$, via the nonlinear interaction between the equi-biaxial stress state of the bond coat imposed by the bond coat-substrate CTE mismatch and the normal traction imposed by the presence of the TGO:

$$
\dot{\delta}=L \dot{\varepsilon_{0}} \exp \left(\frac{-T_{r e f}}{T}\right) \times \frac{p}{\sigma_{0}}\left[a\left(\frac{\sigma_{B C}}{\sigma_{0}}\right)^{n-1}+b\left|\frac{p}{\sigma_{0}}\right|^{n-1}\right]
$$

where $L$ is the rumpling wavelength, $\dot{\varepsilon}_{0}$ is the reference bond coat creep rate, $T_{r e f}$ is the reference temperature for bond coat creep, $\sigma_{0}$ is the reference bond coat creep strength, and $n$ is the creep exponent, $p$ is the magnitude of the sinusoidal normal traction $t=p \cos (\pi x / L)$, and $\sigma_{B C}$ is the magnitude of the bond coat equi-biaxial stress. The coefficients, $a$ and $b$ are functions of the creep exponent, $n$, and represent the nonlinear interaction between the equi-biaxial stress, $\sigma_{B C}$, and the normal traction, $p$. In the $\mathrm{B} \& \mathrm{H}$ simulations $n=4$, which results in $a=0.72$ and $b=0.15$. The TGO behaves elastically in the model, except at the maximum temperature, wherein a yield strength $\sigma_{y}=300 \mathrm{MPa}$ is imposed. The bond coat experiences a significant increase in rumpling amplitude upon heating and then relaxation during the high-temperature hold resulting in an abatement of the rumpled magnitude. Cyclic ratcheting plasticity results in a progressive growth of the rumpling amplitude with continuous cycling. The $\mathrm{B} \& \mathrm{H}$ model has the assumption that TGO growth and creep only occur at maximum temperature and imparts a large contribution of the martensite transition to rumpling growth. 
Model comparisons to the T\&C experiments were made using the Euler time-stepping algorithm described by $\mathrm{B} \& \mathrm{H}$, but using a temperature-dependent CTE for the René N5 substrate [34] and temperature dependent CTE and modulus for the bond coat $[2,39]$. The martensitic transformation is modeled to occur between 550 and $450^{\circ} \mathrm{C}$ during cooling and 600 and $700^{\circ} \mathrm{C}$ during heating as in the original model [4]. The TGO growth is such that the thickness increases from 0.5 to $3 \mu \mathrm{m}$ and the growth strain is a total of $5 \%$ after 100 hours at $1150^{\circ} \mathrm{C}$. Rumpling at a range of wavelengths, $L$, was simulated for every virtual experiment.

The first observation made by $\mathrm{T} \& \mathrm{C}$ is that increasing the hold time at $1150^{\circ} \mathrm{C}$ from 6 minutes to 1 hour to 3 hours, while maintaining the same $200^{\circ} \mathrm{C} / \mathrm{min}$ heating and cooling rates, increases the RMS roughness at the end of 100 cycles from 1 to 3.4 to $4.1 \mu \mathrm{m}$, respectively. Simulating this series of experiments reported by $\mathrm{T} \& \mathrm{C}$ with the $\mathrm{B} \& \mathrm{H}$ model gives a peak rumpling amplitude of about 1.1 to 3.2 to $3.9 \mu \mathrm{m}$ (a ratio of $1: 2.9: 3.5$ ). The predictions for the rumpling amplitude after 100 cycles as a function of wavelength are shown in Figure 11. It should be noted that the comparison between peak rumpling amplitude and RMS roughness is not direct because the RMS roughness is simplified parameter; the trends should be consistent, however. Therefore, to a good approximation, the $\mathrm{B} \& \mathrm{H}$ model does a good job predicting the impact of longer cycle times to rumpling behavior, meaning that the effect of bond coat creep is well captured.

The second observation from the T\&C experiments is that thermal cycling above the martensite transformation temperature $\left(750-1150^{\circ} \mathrm{C}\right)$ causes the same change in RMS roughness as the full temperature range cycle $\left(25-1150^{\circ} \mathrm{C}\right)$ with the same 1-hour hold at temperature. Simulations of this $750 / 1150^{\circ} \mathrm{C}$ cycle give a maximum rumpling amplitude of about $1.1 \mu \mathrm{m}$ compared to 3.2 $\mu \mathrm{m}$ for the $25 / 1150^{\circ} \mathrm{C}$ cycle, Figure 11 . This discrepancy indicates that the $\mathrm{B} \& \mathrm{H}$ model relies too heavily on the biaxial stress caused by the volumetric expansion/contraction of the bond coat upon heating/cooling for rumpling deformation.

The third observation made by T\&C is that the RMS roughness of the bond coat is about $30 \%$ lower when thermal cycling is performed in vacuum compared to cycling in air. The sample was preoxidized in air to form a thin TGO before cycling to limit bond coat vaporization during oxidation in vacuum. This vacuum cycle was modeled by decreasing the TGO growth rate so that the thickness only increases from 0.5 to $0.8 \mu \mathrm{m}$ and the growth strain was a total of $0.1 \%$ after 100 hours at temperature, in close agreement with the experimental observations. As shown in Figure 
11 , the results of this virtual cycle indicate that the maximum rumpling amplitude is only about $0.7 \mu \mathrm{m}$ when cycled in vacuum, which is almost an $80 \%$ decrease in rumpling amplitude compared to the $3.2 \mu \mathrm{m}$ amplitude when cycled in air. This discrepancy indicates that the B\&H model does not sufficiently incorporate the impact of the TGO traction for bond coat deformation.

These two discrepancies are complementary in the $\mathrm{B} \& \mathrm{H}$ model in that they both underestimate the increase in rumpling amplitude resulting from the presence of the TGO. This can be partly rectified in the $\mathrm{B} \& \mathrm{H}$ model by modifying the $a$ and $b$ coefficients. As an example, if $a=0.14$ and $b=34.5$, then the rumpling amplitude of the $750 / 1150^{\circ} \mathrm{C}$ virtual cycle conducted above the martensite transition is increased to $80 \%$ the amplitude of the normal $25 / 1150^{\circ} \mathrm{C}$ cycle (whereas it was only $34 \%$ with the original values of $a$ and $b$ ). However, changes such as this or modifying the high-temperature yield stress of the TGO, cannot bring the $\mathrm{B} \& \mathrm{H}$ model to simultaneously agree with all three of the T\&C experiments. It is possible that the absence of TGO growth and creep at intermediate temperatures is too great a simplification. However, it is likely the B\&H model must be modified to properly account for the effect the presence of a TGO has on the ratcheting amplitude. The experiments by T\&C show that a thin TGO cycled in vacuum provides enough traction or restraint on the bond coat to enable a rumpling amplitude after 100 cycles that is only $30 \%$ smaller than the when cycled in air. In summary, the $\mathrm{B} \& \mathrm{H}$ model is under-predicting the impact of the TGO on the ratcheting plasticity of the bond coat while over predicting for the effect of the equi-biaxial stresses imposed by the martensitic transformation. Nevertheless, the model is useful for assessing trends in the present experiments.

\subsection{BESH model applied to high-strength bond coats}

The effect on rumpling behavior of using a $\gamma^{\prime}$ coating with enhanced strength and TGO growth rate was analyzed using the $\mathrm{B} \& \mathrm{H}$ model (with the original $a$ and $b$ coefficients). In the present work, it is observed that the thermally grown oxides on the $\gamma^{\prime}$ coatings are much thicker than on traditional bond coats. Therefore, it is important to assess the impact of having a thicker TGO along with the change in bond coat strength to understand the nature of rumpling resistance seen in these coatings. This is easily accomplished by changing the creep strength of the bond coat, $\sigma_{0}$, and the growth rate of the TGO in the $\mathrm{B} \& \mathrm{H}$ model. Figure 12 shows a comparison of the final rumpling amplitude after 100 virtual cycles for systems where the TGO grows from 0.5 to 8 $\mu \mathrm{m}$ and/or $\sigma_{0}=100 \mathrm{MPa}$ in comparison to a bond coat with the properties described above. The 
martensitic transformation was not removed from the simulations of the $\gamma^{\prime}$ coatings, even though it would not be present in actual $\gamma^{\prime}$ coatings, because the $\mathrm{B} \& \mathrm{H}$ model relies on the martensitic transition rather than the normal traction of the TGO to emulate rumpling, as explained in Section 5.2. In addition, a 10-minute heating and 2-minute cooling period was used for these simulations to more closely representing the present experiments. The B\&H model indicates that increasing the growth rate of the TGO without changing the bond coat strength increases the rumpling amplitude because the thicker TGO imposes a larger traction on the bond coat, in accordance with unpublished experiments by Tolpygo and Clarke shown in Figure 10 of [4]. As explained in the following section, this rumpling is more pronounced at longer wavelengths. Figure 12 also indicates that increasing the bond coat creep strength drastically inhibits rumpling at all wavelengths. Even with the fastgrowing TGO, the strong bond coat resists rumpling, with only a slight increase in total amplitude over the thin TGO. These simulations corroborate the result found in the present experiments: even with thicker TGOs, the $\gamma^{\prime}$ coatings resist rumpling to a large degree. It is worth noting that the B\&H model can also be used to simulate the effect of adding a thick ceramic thermal barrier coating on rumpling behavior. The model predicts that the TBC drastically inhibits rumpling due to the thick ceramic layer having low out-of-plane compliance, which is generally observed experimentally. The primary differences between a TBC and a TGO are that a TGO has much higher in-plane stiffness and has a growth strain at temperature. These differences lead to increased rumpling with thicker TGO and reduced rumpling under a TBC.

\subsection{Bond Coat Rumpling}

As seen in Figure 9a, the PtAl coating experienced a significantly higher degree of rumpling compared to the two $\gamma^{\prime}$-based coatings. While the presence of rumpling in a Pt-modified NiAl coating is expected at these temperatures $\left(1204^{\circ} \mathrm{C}\right)$, the mechanism(s) responsible for the absence of rumpling in the $\gamma^{\prime}$ coatings are worth consideration. The analytical rumpling model of Balint and Hutchinson [4] has shown that bond coats with thicker TGOs tend to rumple at a faster rate and with a longer wavelength $[40,41]$. However, the present experiments demonstrate that the $\gamma^{\prime}$ coatings have a significantly lower rumpling amplitude increase notwithstanding a larger oxide thickness (based on mass change measurements and micrographs). The rumpling simulations described in Section 5.3 suggest that the $\gamma^{\prime}$ coatings resist rumpling due an increased creep strength. A second consideration is the thermal expansion mismatch between the bond coat and the superalloy. René 
N5 has a CTE around $16-17 \mathrm{ppm} /{ }^{\circ} \mathrm{C}$ at $1200^{\circ} \mathrm{C}$ due to the dissolution of the $\gamma^{\prime}$ precipitates into the Ni matrix $[34,42,43]$. The CTE of the $\gamma^{\prime}$ phase is similar to or lower than the $\beta$ phase at this temperature, which is $2-3 \mathrm{ppm} /{ }^{\circ} \mathrm{C}$ lower than René N5 [43]. This means that the rumpling driving force due to CTE mismatch in a $\gamma^{\prime}$ coating is equal to or larger than a $\beta$ coating.

By comparing the $\gamma^{\prime}$ coating to the $\gamma^{\prime}+\mathrm{Si}$,Ti coating, it is evident that the addition of the high temperature strengtheners, $\mathrm{Si}$ and $\mathrm{Ti}$, leads to a smaller increase in rumpling amplitude during the first 60 cycles (see Figure 9a), in accordance with the calculations performed in this work. The decrease in the rumpling amplitude after 60 cycles for the $\gamma^{\prime}+\mathrm{Si}$,Ti coating is likely due to the breakaway oxidation that occurs in this coating as indicated by the increase in TGO spalling rate in Figure 6b. Therefore, it is likely that bond coatings with the $\gamma^{\prime}$ phase experience less rumpling than $\beta$-phase coatings by increasing the high-temperature strength. It is also possible that the creep properties (and therefore the growth stress) of the TGO are modified by the presence of $\mathrm{HfO}_{2}$ particles and voids in the TGO. Although not demonstrated in this work, the $\mathrm{B} \& \mathrm{H}$ model indicates that decreasing the TGO growth stress leads to a decrease in rumpling amplitude. It is also expected that an increase in the TGO bending stiffness with no change in TGO growth stress would inhibit rumpling.

Balint and Hutchinson determined that the primary rumpling wavelength should scale with the properties of the TGO [4]:

$$
L^{*} \propto h \sqrt{\frac{\pi^{2} \bar{E}}{12 \sigma_{y}}}
$$

where $h$ is the TGO thickness, $\bar{E}$ is the biaxial elastic modulus of the TGO, and $\sigma_{y}$ is the high temperature yield strength (growth stress) of the TGO. This represents a balance between the elastic energy stored in the compressed film and the bending resistance due to stiffness. A plot of the wavelength as a function of cycles for the coatings is in Figure 9b. This plot shows the primary wavelength $L^{*}$ of the surface topology as a function of cycles at $1204^{\circ} \mathrm{C}$. Figure 9a shows the relative amplitude of this peak. Clearly, the wavelength of the $\gamma^{\prime}$ and $\gamma^{\prime}+\mathrm{Si}$,Ti coatings continuously increased as a function of cycles while maintaining a relatively stable amplitude. (It should be emphasized that there was very little rumpling measured in the $\gamma^{\prime}$ coatings so the determination of the "peak" wavelength is subject to a larger uncertainty). The PtAl coating, however, has a consistent wavelength of about $80 \mu \mathrm{m}$ but an amplitude that is continuously increasing. This contrast can be explained by the rate at which the respective TGO scales grew on the coatings. 
According to Balint and Hutchinson, once a primary rumpling wavelength has been established it is difficult to suppress it. This is seen in the $\mathrm{PtAl}$ sample where the slow-growing oxide scale has ample time to establish and settle on a primary wavelength before the oxide thickness increases so significantly as to change the preferred wavelength. That is to say that the rumpling "inertia" in a slow growing scale is difficult to overcome. On the other hand, the $\gamma^{\prime}$ coatings have much faster growing scales and have a larger impact on rumpling wavelength stability during thermal cycling; this results in a small rumpling amplitude with a continuously increasing wavelength, per Equation 3 .

\subsection{Comparison to Pt-modified $\gamma+\gamma$ Coatings}

Recent research on the oxidation and rumpling properties of Pt-containing $\gamma+\gamma^{\prime}$ bond coats has shown that this phase combination is also resistant to rumpling deformation at the expense

of slightly faster oxidation rate than the $\beta$-phase $(\mathrm{Ni}, \mathrm{Pt}) \mathrm{Al}$ coatings [44-46]. These experiments were performed at $1150^{\circ} \mathrm{C}$ on two-phase coatings that were in the Al-rich side of the $\gamma+\gamma^{\prime}$ phase field. There is a delicate balance between the $\mathrm{Pt}$ and $\mathrm{Hf}$ concentrations that causes the growth of $\mathrm{NiAl}_{2} \mathrm{O}_{4}$ formation over the $\mathrm{Al}_{2} \mathrm{O}_{3}$ scale and $\mathrm{HfO}_{2}$ pegs beneath the scale [44]. The presence of hafnia pegs was associated with Ni-spinel growth in these experiments [44].

The behavior of the nominally single-phase $\gamma^{\prime}$ coatings examined here is similar to the Ptmodified two-phase $\gamma+\gamma^{\prime}$ with respect to rumpling resistance and the development of a corundum scale with Ni-spinel above it. Pt modification would likely improve the oxidation and corrosion properties by enhancing a slow-growing, dense alumina scale. It is, therefore, possible that Ptmodification to the single-phase $\gamma^{\prime}$ coatings would also have a beneficial effect on the oxidation behavior, perhaps at a lower $\mathrm{Pt}$ concentration due to the higher initial concentration of $\mathrm{Al}$. A direct comparison of TBC retention for both optimized single- and two-phase coatings is of interest for future work.

\section{Conclusions}

The $1204^{\circ} \mathrm{C}$ oxidation behavior of two experimental $\gamma^{\prime}$ coatings has been analyzed. The changes in mass, oxidation spalling, surface roughness, and rumpling have been quantified and compared to a standard $(\mathrm{Pt}, \mathrm{Ni}) \mathrm{Al}$. The $\gamma^{\prime}$ phase was found to be more resistant to rumpling than the Ptmodified $\beta$ phase coating. The resistance to rumpling is best understood as arising from improved 
creep properties. The $\gamma^{\prime}$ coating was more resistant to TGO spalling from the surface of the bond coat than the PtAl coating throughout the test, despite the formation of a thicker oxide. While the $\gamma^{\prime}$-phase coatings oxidize faster than the PtAl coating under the conditions examined, it will be shown in a future publication that the $\gamma^{\prime}$ coatings can be more resistant to TBC failure at elevated temperatures.

\section{Acknowledgments}

The authors are indebted to Scott Weaver, Ernie Hearn, Yan Gao, Anjali Singhal, and Jeremy McNamara of GE Global Research for assistance with the production, testing, and characterization of the coatings presented in this work. This work was supported under NSF grant DMR 1105672. The MRL Shared Experimental Facilities are supported by the MRSEC Program of the NSF under Award No. DMR 1121053; a member of the NSF-funded Materials Research Facilities Network (www.mrfn.org).

\section{References}

[1] Reed RC. The Superalloys: fundamentals and applications. Cambridge University Press, 2006.

[2] Pan D, Chen M, Wright P, Hemker K. Acta Materialia 2003;51:2205.

[3] Mumm D, Evans A, Spitsberg I. Acta Materialia 2001;49:2329.

[4] Balint D, Hutchinson J. Journal of the Mechanics and Physics of Solids 2005;53:949.

[5] Tolpygo VK, Clarke D. Acta Materialia 2004;52:5115.

[6] Balint D, Hutchinson J. Acta Materialia 2003;51:3965.

[7] Karlsson AM, Hutchinson J, Evans A. Materials Science and Engineering: A 2003;351:244.

[8] Karlsson AM, Levi C, Evans A. Acta Materialia 2002;50:1263.

[9] Karlsson AM, Evans A. Acta Materialia 2001;49:1793.

[10] Tolpygo VK, Clarke D. Acta Materialia 2004;52:5129. 
[11] Pollock TM, Laux B, Brundidge CL, Suzuki A, He MY. Journal of the American Ceramic Society 2011;94:s136.

[12] Suzuki A, Gigliotti M, Hazel B, Konitzer D, Pollock T. Metallurgical and Materials Transactions A 2010;41:947.

[13] He M, Evans A. Acta Materialia 2010;58:583.

[14] Evans A, He M, Suzuki A, Gigliotti M, Hazel B, Pollock T. Acta Materialia 2009;57:2969.

[15] Sastry D, Sundar R. In: S Deevi, R Cahn, V Sikka, P Maziasz (Eds.), International Symposium on Nickel and Iron Aluminides: Processing, Properties and Applications. Metals Park, OH: ASM International International, 1997, 123-144.

[16] Hancock G. Physica status solidi (a) 1971;7:535.

[17] Hancock G, McDonnel B. Physica status solidi (a) 1971;4:143.

[18] Hemker K, Nix W. Metallurgical Transactions A 1993;24:335.

[19] Miracle D. Acta Metallurgica et Materialia 1993;41:649.

[20] Darolia R, Walston W. Intermetallics 1996;4:505.

[21] Pollock T, Field R. Dislocations in Solids 2002;11:547.

[22] Noebe R, Bowman R, Nathal M. International Materials Reviews 1993;38:193.

[23] Pettit F. Transactions of the Metallurgical Society of AIME 1967;239:1296.

[24] Giggins C, Pettit F. Journal of the Electrochemical Society 1971;118:1782.

[25] Gleeson B, Mu N, Hayashi S. Journal of Materials Science 2009;44:1704.

[26] Alvin MA, Klotz K, McMordie B, Zhu D, Gleeson B, Warnes B. Journal of Engineering for Gas Turbines and Power 2014;136:112102.

[27] Thermo-Calc software database TCNI5 Ni-based superalloys version 5.

[28] Tsipas D, Lefakis H, Rawlings R, Staton-Bevan A, Tsipas S. Materials and Manufacturing Processes 2001;16:127. 
[29] Rawlings RD, Staton-Bevan AE. Journal of Materials Science 1975;10:505.

[30] Lowell CE, Santoro GJ. Technical Note D-6838, NASA, 1972.

[31] Hazel B, Rigney J, Gorman M, Boutwell B, Darolia R. Superalloys 2008;:753.

[32] Zhang X, Wang S, Gesmundo F, Niu Y. Oxidation of Metals 2006;65:151.

[33] Wu Y, Niu Y, Wu Wt. Trans Nonferrous Met Soc China 2005;15.

[34] Pollock T, Lipkin D, Hemker K. MRS Bulletin 2012;37:923.

[35] Jorgensen D, Jackson R, Pollock T. Surface and Coatings Technology 2016;submitted.

[36] Tolpygo V, Murphy K, Clarke D. Acta Materialia 2008;56:489.

[37] Jackson R, Lipkin D, Pollock T. Surface and Coatings Technology 2013;221:13.

[38] Bannister MJ, Barnes JM. Journal of the American Ceramic Society 1986;69.

[39] Chen M, Ott R, Hufnagel T, Wright P, Hemker K. Surface and Coatings Technology 2003; 163-164:25.

[40] Tolpygo VK, Clarke D. Acta Materialia 2004;52:615.

[41] Balint D, Xu T, Hutchinson J, Evans A. Acta Materialia 2006;54:1815.

[42] Tryon B, Pollock T, Gigliotti M, Hemker K. Scripta Materialia 2004;50:845.

[43] Haynes J, Pint B, Porter W, Wright I. Materials at High Temperatures 2004;21:87.

[44] Izumi T, Mu N, Zhang L, Gleeson B. Surface and Coatings Technology 2007;202:628.

[45] Zhang Y, Ballard D, Stacy J, Pint BA, Haynes JA. Surface and Coatings Technology 2006; 201:3857.

[46] Deodeshmukh V, Mu N, Li B, Gleeson B. Surface and Coatings Technology 2006;201:3836. 
Table 1: Composition (in atomic \%) of the experimental coatings designed using the CalPhaD approach and subsequently synthesized experimentally. Compositions were measured by X-Ray fluorescence (XRF) and microprobe (EPMA) in the as-coated condition. The sulfur and carbon concentrations were measured by glow discharge mass spectroscopy (GDMS) at Evans Analytical Group and are listed in ppmw.

\begin{tabular}{ccccccccccc}
\hline & (at\%) & $\mathrm{Ni}$ & $\mathrm{Al}$ & $\mathrm{Cr}$ & $\mathrm{Ta}$ & $\mathrm{Hf}$ & $\mathrm{Ti}$ & $\mathrm{Si}$ & $\mathrm{C}(\mathrm{ppmw})$ & $\mathrm{S}(\mathrm{ppmw})$ \\
\cline { 3 - 11 } & EPMA & 69.4 & 24.0 & 3.3 & 2.0 & 0.63 & - & - & 720 & 2.1 \\
$\gamma^{\prime}$ & $\mathrm{XRF}$ & 70.8 & 24.1 & 1.8 & 2.6 & 0.73 & - & - & & \\
$\gamma^{\prime}+\mathrm{Si}, \mathrm{Ti} i$ & EPMA & 67.9 & 24.0 & 3.3 & 2.4 & 0.67 & 0.90 & 0.60 & \multirow{2}{*}{1060} & 4.1 \\
& $\mathrm{XRF}$ & 68.9 & 24.9 & 1.8 & 2.6 & 0.75 & 0.80 & 0.40 & & \\
\hline
\end{tabular}




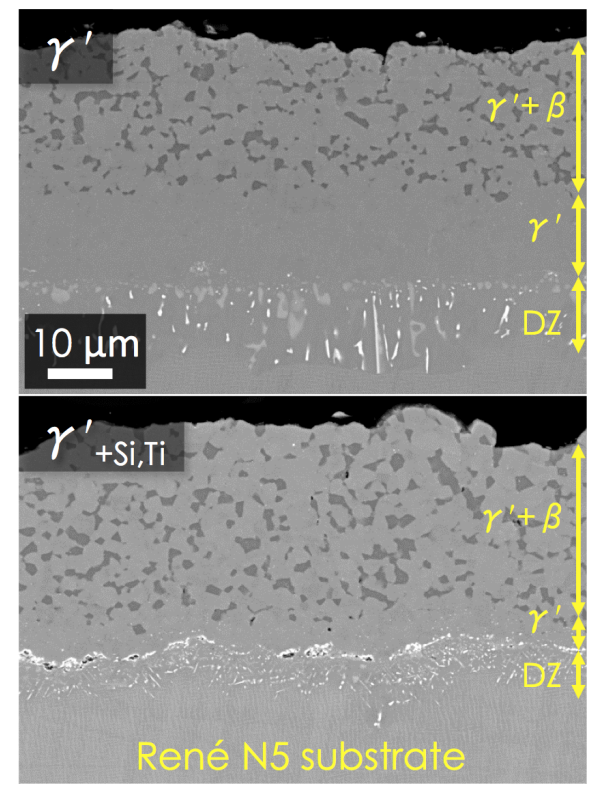

Figure 1: Cross sections showing the coating micostructures of the two experimental coatings having the compositions shown in Table 1. Both coatings have been coated by ion plasma deposition and heat treated for four hours in vacuum at $1080^{\circ} \mathrm{C}$. The $\gamma^{\prime}$ and $\gamma^{\prime}+\mathrm{Si}$,Ti coatings were deposited with a two-phase $\gamma^{\prime}+\beta$ microstructure, which transitions to single-phase $\gamma^{\prime}$ as Al diffuses from the coating into the substrate. A diffusion zone (DZ) containing refractory metal precipitates is present below the coatings. 

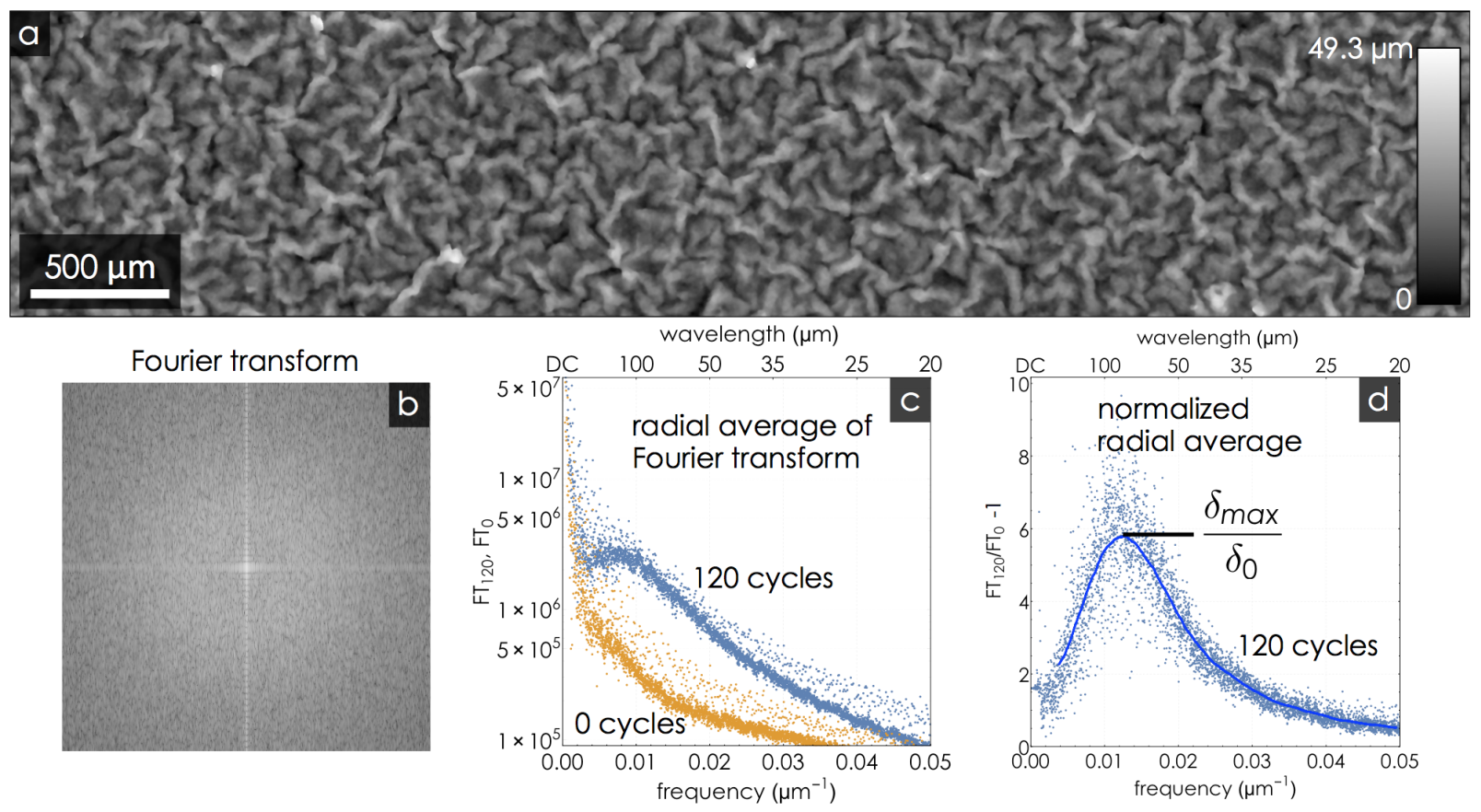

Figure 2: PtAl coating surface after 120 cycles at $1204^{\circ} \mathrm{C}$ as an example of the Fourier transform surface analysis. (a) Optical profilometer scan of the surface oxide. (b) Low-frequency center of the 2D Fourier transform of the surface profile measurement. The logarithm of the individual matrix values has been taken and the total range has been scaled between 0 and 244. A diffuse donut-shaped peak is visible that correlates to the peaks seen in c and d. (c) Radial average of the transformed profile at 0 cycles and 120 cycles. Individual pixel values were grouped together in 0.1 pixel radii bins and averaged. (d) The 120-cycle radial average normalized by the 0 -cycle radial average. The normalization is $\left(\mathrm{FT}_{120 \mathrm{c}} / \mathrm{FT}_{0 \mathrm{c}}-1\right)$ so that the relative increase is shown. The solid line is a 500-point moving average showing an increase in primary wavelength of approximately $95 \mu \mathrm{m}$ with an amplitude that has grown about six-fold versus the original value. This indicates significant rumpling of the bond coat. The curve is analogous to the analytical analysis presented in Figure 9 of Balint and Hutchinson [4]. 


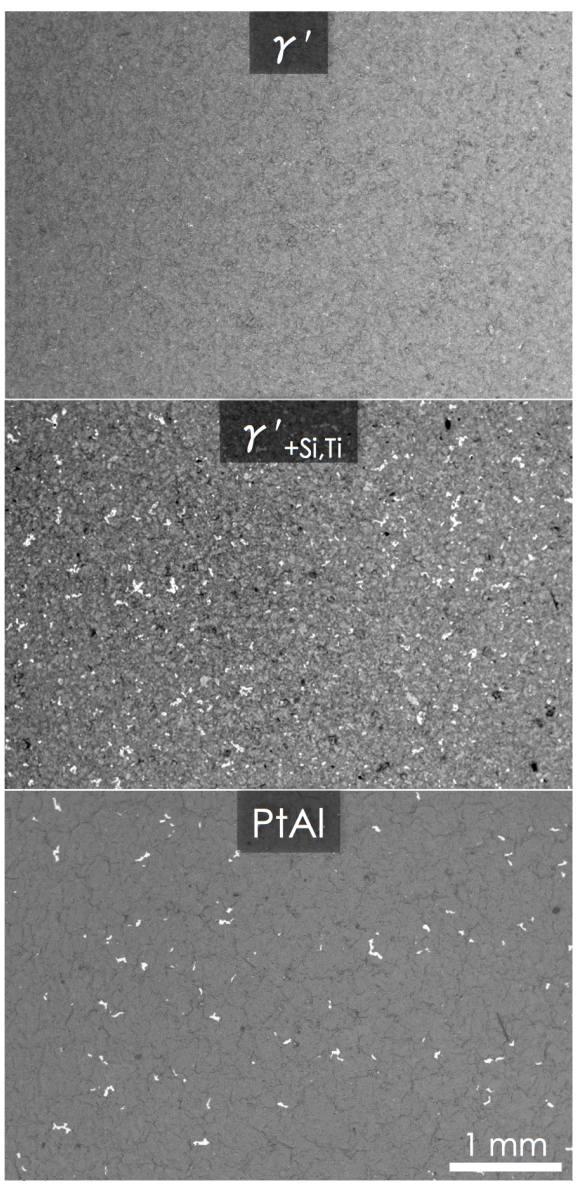

Figure 3: Backscattered electron images showing the plan view of the samples after 120 cycles at $1204^{\circ} \mathrm{C}$. The lighter contrast in each image is the exposed bond coat surface due to spalling of the TGO. After 120 cycles, the $\gamma^{\prime}$ coating shows the least amount of freshly exposed bond coat, followed by PtAl, and $\gamma^{\prime}+\mathrm{Si}, \mathrm{Ti}$. 


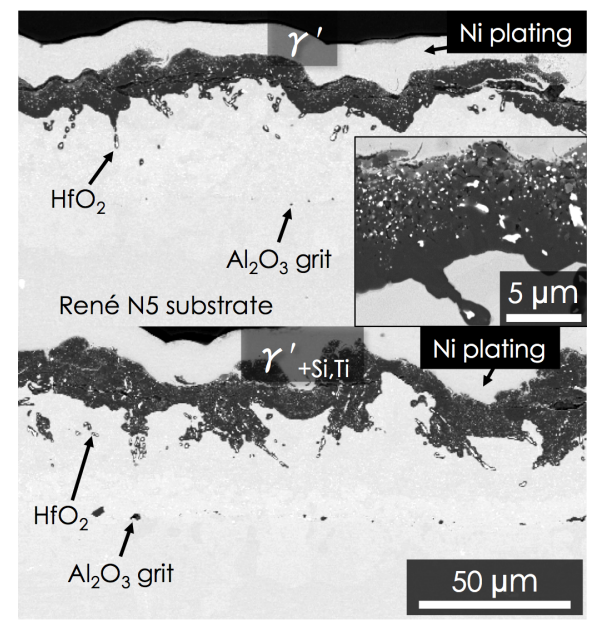

Figure 4: Cross sections of the coatings after 60 cycles at $1204^{\circ} \mathrm{C}$. The coatings have selective oxidation of Hf beneath the oxide scale to form $\mathrm{HfO}_{2}$ pegs. Both of the coatings exhibit oxidation that is non uniform, creating TGOs that have significant variations in thickness. The inset in the upper image shows the porosity gradient in the TGO from the $\gamma^{\prime}$ sample in detail. The bottom of the TGO is more dense than the top, where there are more intermixed hafnia particles. 


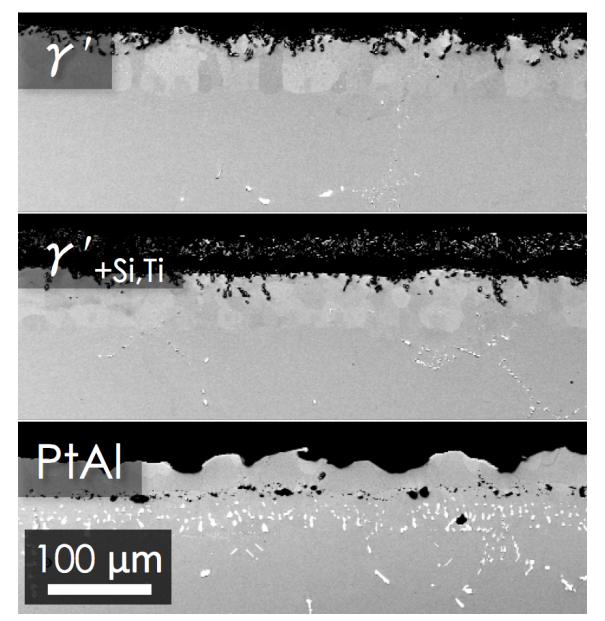

Figure 5: Cross sections of the coatings after 120 cycles at $1204^{\circ} \mathrm{C}$. The PtAl standard coating experienced significant rumpling while the $\gamma^{\prime}$ and $\gamma^{\prime}+\mathrm{Si}$,Ti coatings did not. Both the $\gamma^{\prime}$ and $\gamma^{\prime}+\mathrm{Si}$, Ti coatings had internal oxidation of Hf near the surface, but the PtAl coating did not. While neither of the experimental coatings exhibited an interdiffusion zone or formation of TCP phases at 120 cycles, the PtAl coating did. 


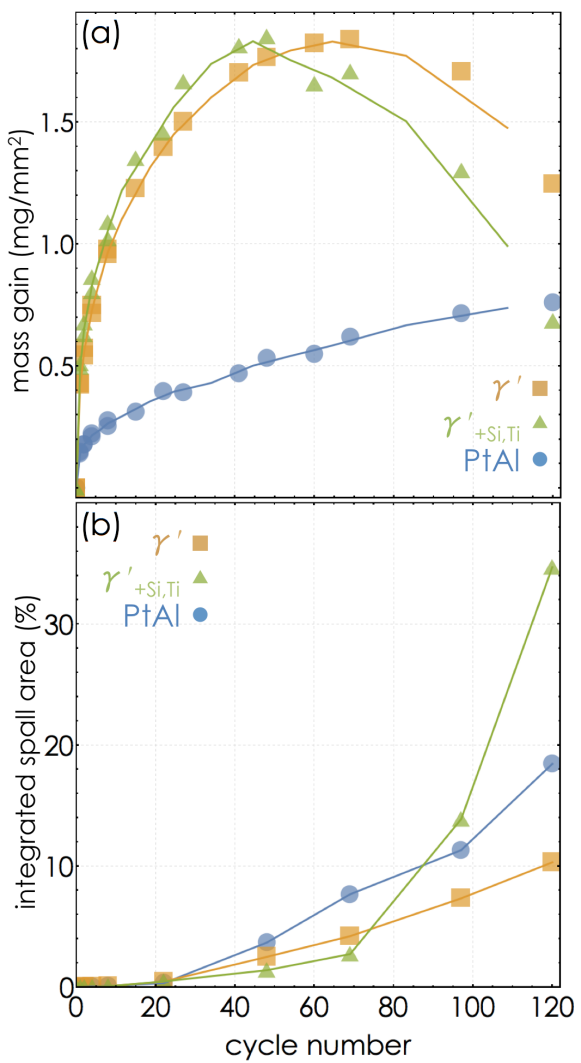

Figure 6: (a) The mass gain of the two experimental coatings and the PtAl standard as a function of thermal cycles. The solid lines are 2-point moving averages. (b) Plot of the spalled oxide area fraction measurements integrated over all cycles at $1204^{\circ} \mathrm{C}$. 


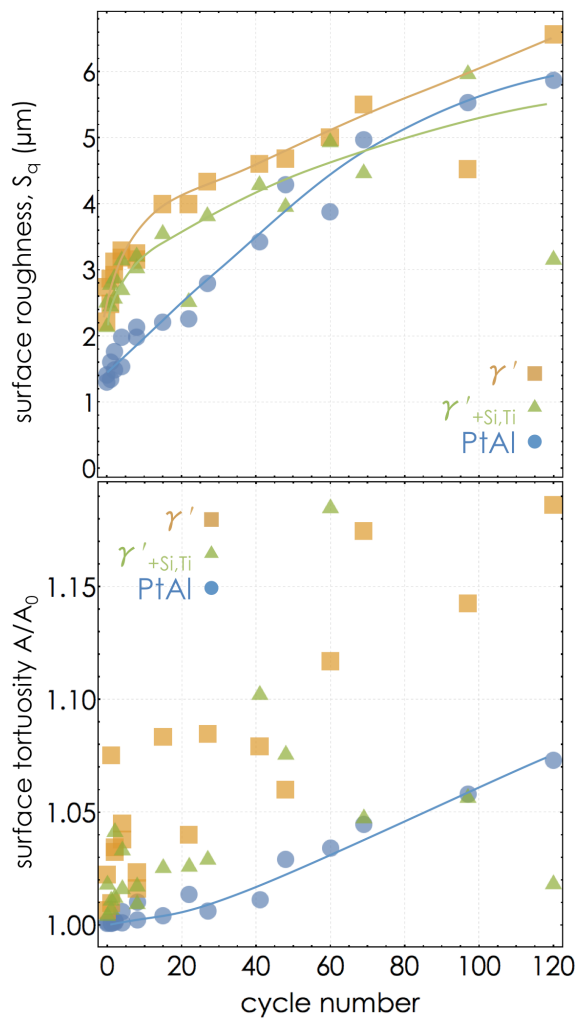

Figure 7: (a) The RMS surface roughness, $\mathrm{S}_{\mathrm{q}}$ and (b) 2D surface tortuosity as a function of one-hour cycles at $1204^{\circ} \mathrm{C}$ for the three bond coats tested. All coatings shows similar $\mathrm{S}_{\mathrm{q}}$ behavior while only the PtAl coating shows a surface tortuosity trend. The absence of a trend three experimental is likely due to the large amount of scatter due to formation of locally thick regions (mounds) in the TGO as seen in Figure 8 and local spalling of the oxide as seen in Figure 3. 


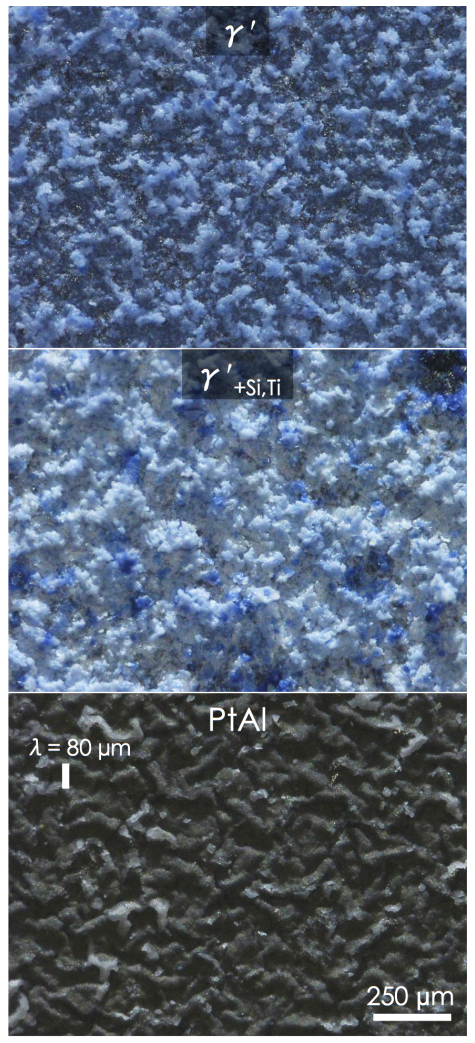

Figure 8: Light optical images of the external oxide scales of the bond coated samples after 120 cycles at $1204^{\circ} \mathrm{C}$. $\mathrm{NiAl}_{2} \mathrm{O}_{4}$ appears as dark blue, $\mathrm{Al}_{2} \mathrm{O}_{3}$ appears as grey, and $\mathrm{TiO}_{2}$ rutile is pale blue. The large-amplitude undulations in the rumpled PtAl bond coat are clearly visible with a primary wavelength of $80 \mu \mathrm{m}$. 

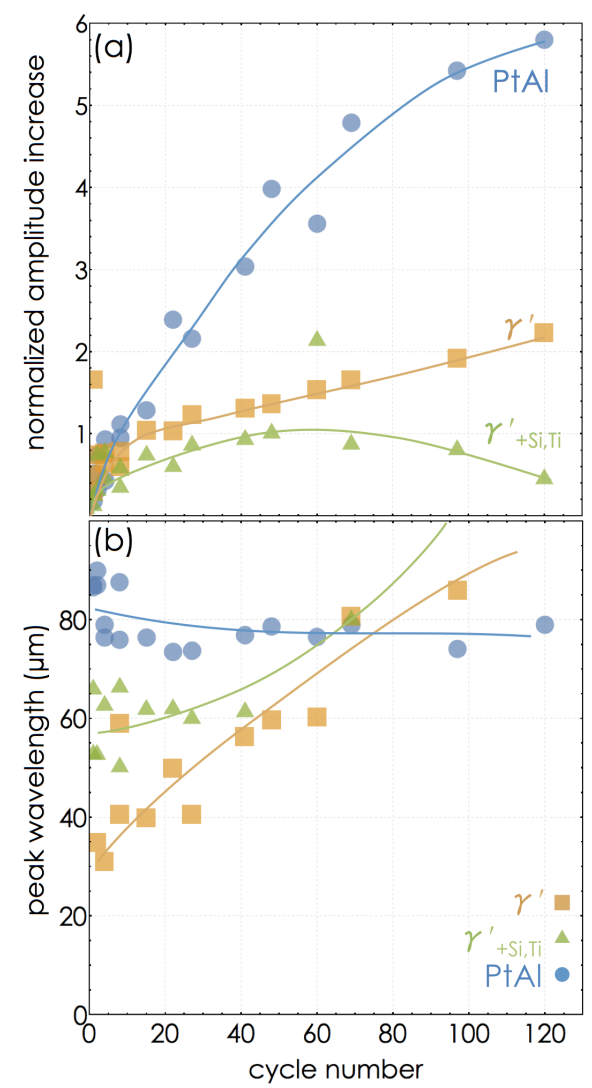

Figure 9: (a) The amplitude of the peak value from the FT-analyzed surfaces $\left(\delta_{\max } / \delta_{0}\right)$. This measure of bond coat rumpling is insensitive to surface roughness effects, such as may be due to poor oxidation behavior. The curves are drawn to guide the eye for trends of the three coatings. (b) Evolution of the wavelength of the FT peak as a function of cycles. The PtAl coating, with a slow-growing scale, experienced rumpling at a relatively constant wavelength of about 75-80 $\mathrm{m}$ that continuously increased in amplitude. In contrast, the $\gamma^{\prime}$ coatings, which had fast-growing TGOs, had a significantly smaller surface undulation amplitude that continuously increased in wavelength. The peak location for the $\gamma^{\prime}+\mathrm{Si}$, Ti sample was longer than $200 \mu \mathrm{m}$ after 80 cycles and is not shown because it was too close to the DC shift of the transform to be differentiated. This is characteristic of a mostly flat bond coat surface, consistent with Figure 5. Lines are drawn to guide the eye. 
(a) $\gamma^{\prime}$

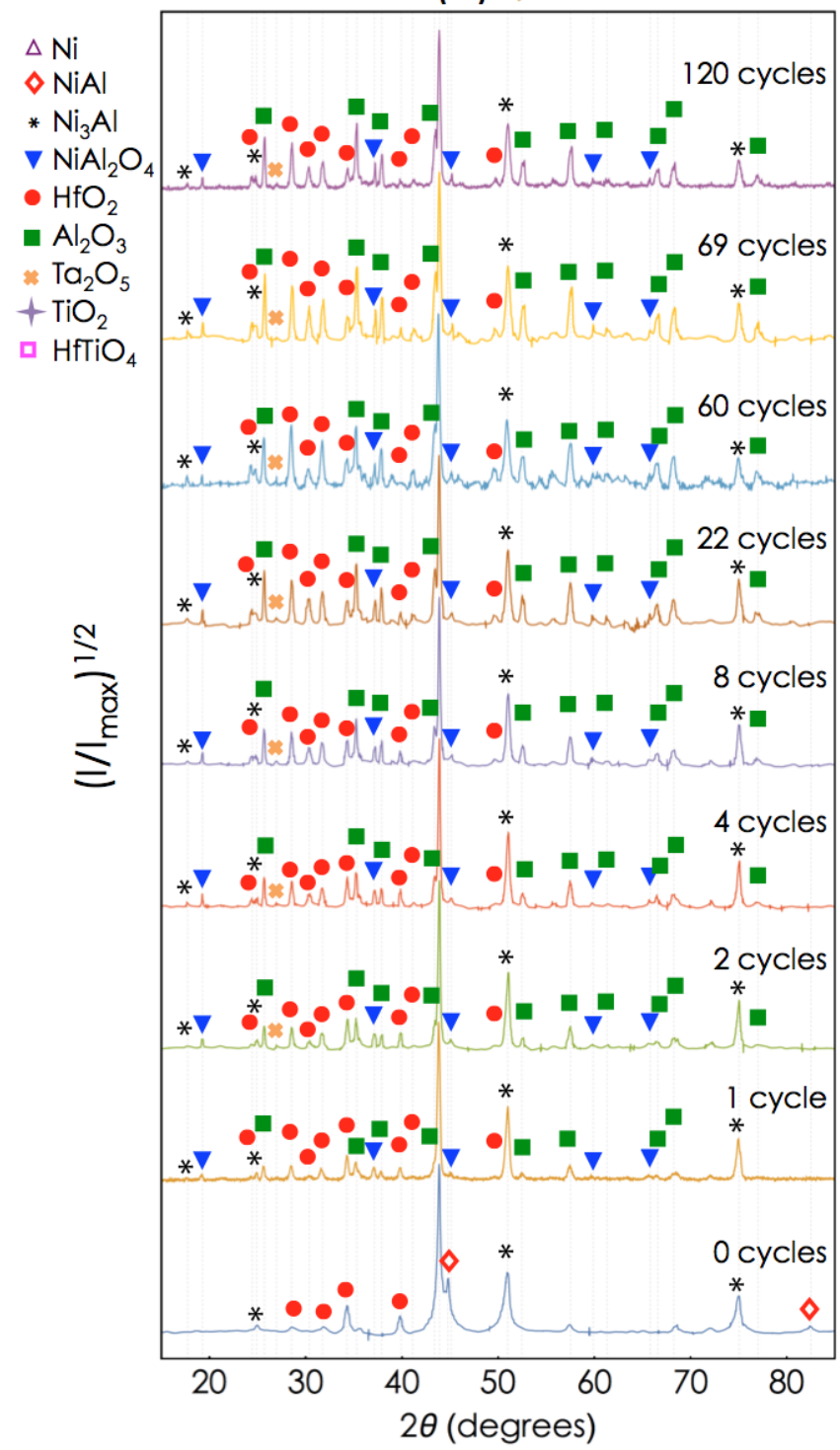

(b) $\gamma_{+S i T i}^{\prime}$

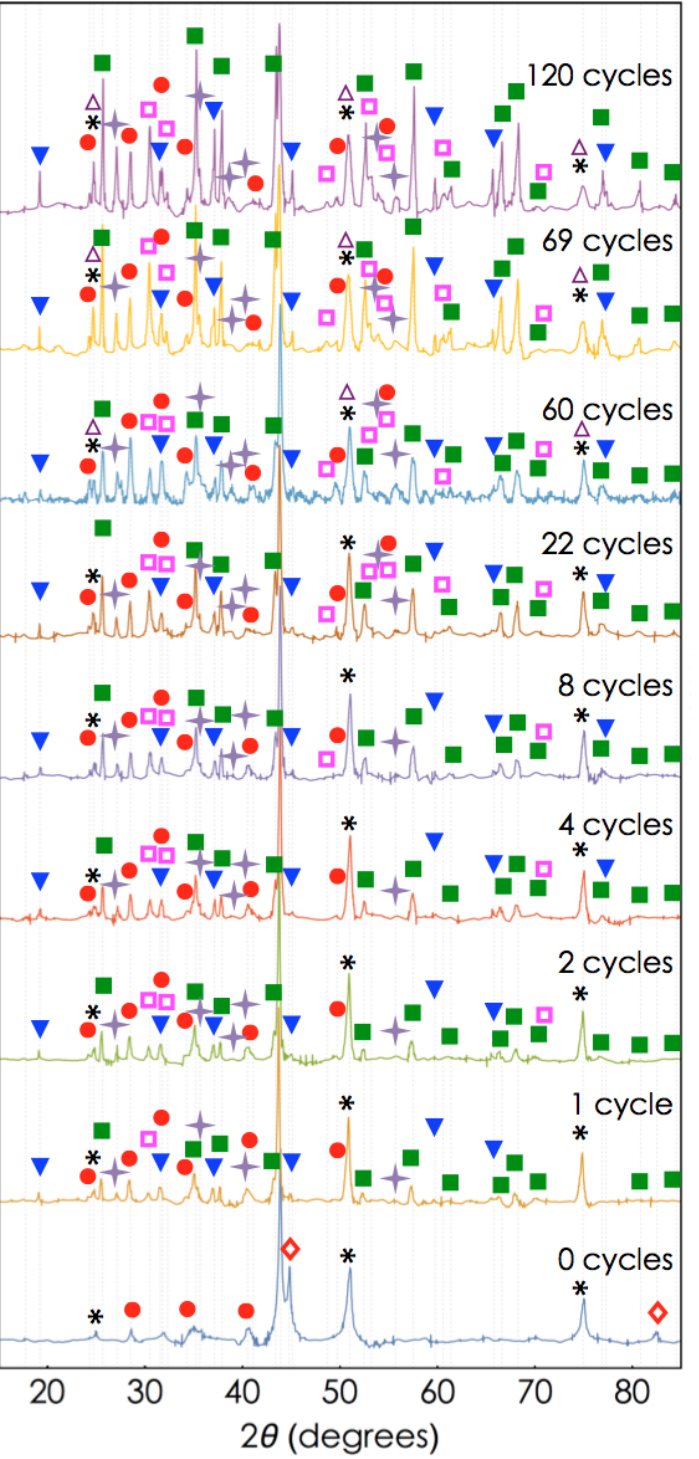

Figure 10: X-ray diffraction (XRD) normalized intensity as a function of $2 \theta$ for the (a) $\gamma^{\prime}$ and (b) $\gamma^{\prime}+\mathrm{Si}$,Ti coatings at selected cycles. Both of the $\gamma^{\prime}$ coatings were slightly Al-rich after deposition and heat treatment, which resulted in the presence of NiAl until after the first cycle. The spinel $\left(\mathrm{NiAl}_{2} \mathrm{O}_{4}\right)$ in the $\gamma^{\prime}$ coating became increasingly enriched in Co in the last 50 cycles of the test as measured by the peak shifts. 


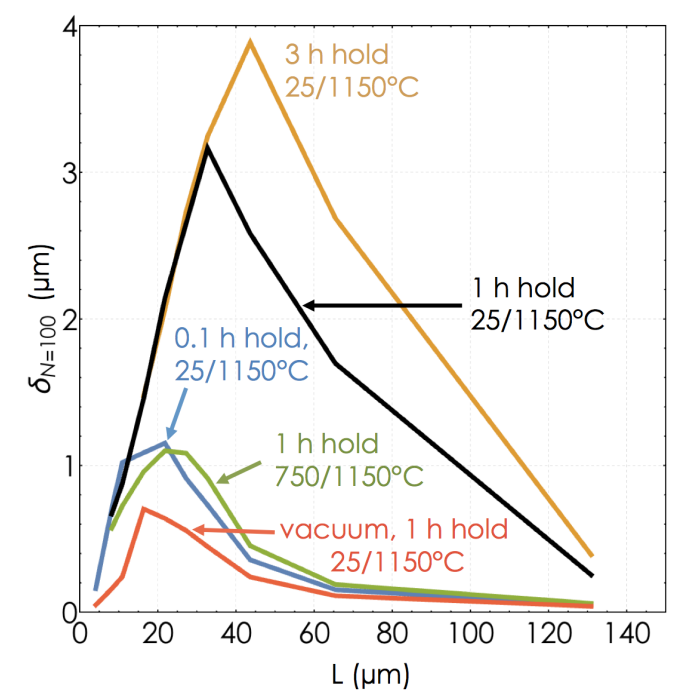

Figure 11: Rumpling amplitude after one hundred cycles calculated using the B\&H model modified to represent the experiments conducted by $\mathrm{T} \& \mathrm{C}[5]$. 


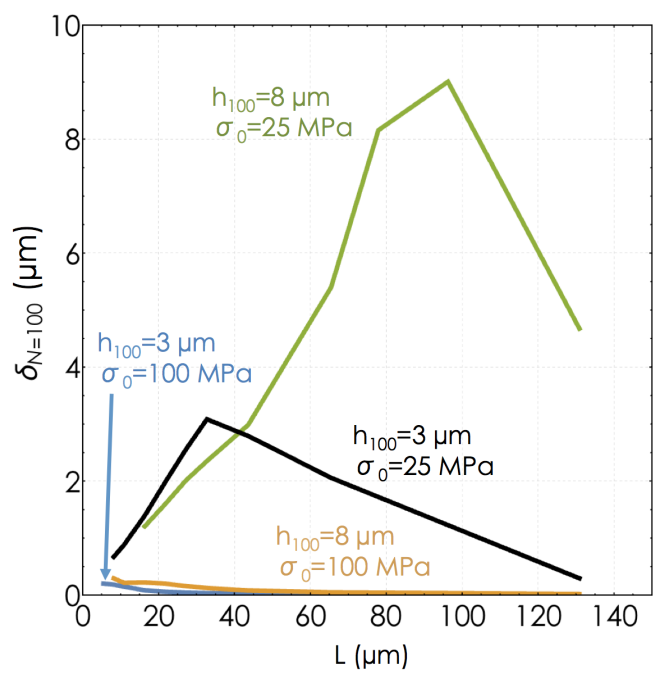

Figure 12: Rumpling amplitude after 100 cycles, calculated using the modified B\&H model to examine the effect of increasing the TGO growth rate and bond coat creep strength, $\sigma_{0}$. The parameter $\mathrm{h}_{100}$ is the final TGO thickness after 100 cycles. All virtual cycles have a 1 hour hold at temperature and are conducted between $25-1150^{\circ} \mathrm{C}$. 